\title{
Cenplasto
}

\section{Comunicação Organizacional e Gestão do Conhecimento: interface entre áreas}

\author{
Ariane Barbosa Lemos \\ Doutora; Universidade do Estado de Minas Gerais, Divinópolis, MG, Brasil; \\ ariane.lemos@uemg.br \\ Ricardo Rodrigues Barbosa \\ Doutor; Universidade Federal de Minas Gerais, Belo Horizonte, MG, Brasil; \\ rrbarb@gmail.com
}

\begin{abstract}
Resumo: O trabalho relata uma pesquisa, de natureza interdisciplinar, que descreve práticas e abordagens gerenciais da comunicação organizacional e da gestão do conhecimento, identificando interface entre as áreas. Trata-se de uma pesquisa descritiva, com base em um estudo de caso realizado em uma empresa do setor de serviços e produtos de aluguel de automóveis. Os dados obtidos referendam os paradigmas relacional da comunicação e do conhecimento organizacional como os mais adequados para a promoção do diálogo interpessoal no ambiente do trabalho. O estudo evidencia a importância da formação de contextos capacitantes propícios para o compartilhamento da informação e a criação de conhecimento no âmbito da organização estudada. Os resultados demonstram que os contextos capacitantes estimulam a promoção do compromisso dos públicos internos para com a organização, a conscientização sobre mudanças no ambiente corporativo, a compreensão da evolução dos objetivos organizacionais e a sensação de pertencimento à organização. Os resultados também evidenciam a relevância da comunicação interna para o compartilhamento da informação e a criação de conhecimento organizacional.
\end{abstract}

Palavras-chave: Comunicação interna. Compartilhamento de informação. Criação de conhecimento. Contexto capacitante. Interdisciplinaridade.

\section{Introdução: o desafio de compartilhar informação e gerar conhecimento organizacional}

Quando surgiu na literatura da Ciência da Informação, na segunda metade da década de 1990, a temática gestão do conhecimento se apresentou como uma possibilidade de investigação sobre o fenômeno do gerenciamento e compartilhamento do conhecimento organizacional (BARRETO, 2005). No entanto, trilhar o caminho em direção a novos posicionamentos sobre a gestão do 
conhecimento trouxe questionamentos sobre como gerir algo intangível e materializado apenas na mente das pessoas: o conhecimento. Buscar respostas para indagações dessa natureza significa traspor o entendimento do "como gerir" o conhecimento organizacional para o "como promover" a externalização do conhecimento individual e, assim, fomentar a criação de conhecimento no ambiente corporativo.

Autores interessados nessa temática, a exemplo de Nonaka e Takeuchi (1995), Choo (1998) e Davenport e Prusak (1998) manifestaram, em seus estudos, o aspecto cognitivo da criação do conhecimento relacionado com a assimilação de informações resultantes da interpretação individual e subjetiva. Nos trabalhos assinados por esses autores, a tríade dado-informação-conhecimento é bastante evidenciada. Sob essa perspectiva, um dado pode ser observado, enquanto uma informação é resultado cognitivo de uma interpretação ou reflexão e o conhecimento construído subsidia uma ação, uma decisão.

Cabe dizer que a temática da gestão do conhecimento encontra um amplo respaldo na literatura, incluindo estudos sobre a participação da comunicação no gerenciamento da informação e do conhecimento. Pizzaia et al. (2018), por exemplo, discutem os aspectos da comunicação presentes em sete modelos de gestão do conhecimento. A análise apresentada pelos autores observou que a comunicação contribui no sentido de mitigar ruídos, mas, por outro lado, indica que nenhum dos modelos estudados foi capaz de demonstrar a efetividade da comunicação na geração de conhecimento novo e útil para as organizações. Associando a gestão do conhecimento à inovação, parte-se do pressuposto de que existem nas organizações, pelo menos, dois tipos de comunicação: a processual, técnica, representada por canais, setores e protocolos; e a relacional, indicando o fenômeno da interação social das relações dialógicas, fundamentais para a troca de informação e criação de conhecimento. Este relato de investigação busca ampliar essa reflexão.

Este artigo tem como objetivo principal identificar iniciativas de compartilhamento da informação e criação de conhecimento em determinado ambiente organizacional e descrever ferramentas da gestão do conhecimento e da comunicação organizacional. Em especial, o artigo problematiza, com base em 
um estudo de caso, a interferência ou não de práticas da comunicação organizacional nos diferentes processos de produção, apropriação, organização e circulação de informações no ambiente corporativo.

\section{Ciências da Comunicação: paradigmas e aplicação no contexto organizacional}

No ambiente organizacional, é notória a influência dos processos comunicativos nos processos administrativos. Ao dedicar capítulo à natureza e às funções da comunicação, Simon (1971, p. 161) afirmou que a comunicação poderia: “[...] ser formalmente definida como o processo mediante o qual as premissas decisórias são transmitidas de um membro da organização para outro.”. Tal visão endossa o viés tecnicista da comunicação na base do paradigma clássico da comunicação, também conhecido como paradigma informacional. Esse paradigma tem origem na Teoria Matemática da Informação, de Claude Shannon (SHANNON; WEAVER, 1972) e enaltece a mecanicidade e a linearidade no processo comunicativo de transmissão de mensagens em qualquer contexto, inclusive o organizacional. Nessa perspectiva, a comunicação se concretiza na transferência de uma mensagem, composta de certo número de sinais, emitidos por uma fonte a um receptor, através de um canal físico e sujeita a ruídos.

A mecanicidade e a lineariedade desse processo comunicativo traz limitações ao paradigma informacional, sobretudo no que se refere ao caráter sistêmico de interrelações pessoais. Um estudo que ilustra essa percepção foi feito por Drigo et al. (2020) no contexto de uma empresa do ramo petroquímico e atuante no Brasil. A pesquisa desenvolveu uma modelagem de equações estruturais para analisar a comunicação de nível operacional da empresa, considerando como variáveis a gestão do conhecimento (exógena e independente) e a comunicação escrita, a comunicação oral e a interação do homem com as TICs (dependentes). A partir dos achados da pesquisa, as limitações indicam que:

[...] a comunicação sobre o chão de fábrica depende de ações organizacionais efetivas para gerenciamento de informações. Recomenda-se que a organização inclua em sua política de 
informação, informações estratégias de comunicação humana no setor operacional. (DRIGO et al., 2020, p. 121720, tradução nossa).

Outro apontamento dos autores recomenda a realização de treinamentos amparados em técnicas de comunicação interna. Como será visto a seguir, a comunicação interna pode ser aplicada como uma ferramenta estratégica no que tange ao compartilhamento da informação e à geração de conhecimento.

Analisando o processo comunicativo pela ótica do paradigma informacional e aplicado no contexto organizacional, Lima e Bastos (2008, p. 06) defendem que:

[...] um processo transmissional em que um emissor [geralmente, a organização] cria mensagens [desenvolve um planejamento de ações comunicacionais, elabora seu conteúdo, seleciona os canais e a forma na qual a interação deve ocorrer] que são divulgadas através de meios de comunicação [veículos próprios de mídia de massa] e direcionadas a seus receptores [seus públicos-alvo], buscando-se sempre a maior eficácia do processo [menor ruído, o mínimo de imprevisibilidade].

Conforme demonstram as autoras, o paradigma clássico da comunicação evoca uma visão de passividade por parte de quem recebe e, consequentemente, consome as mensagens/informações. Sob essa perspectiva, o processo transmissional descrito é frágil, tendo em vista que o consumo e a retenção de mensagens, na verdade, dependem da subjetividade de cada participante do processo comunicativo. Assim, a linearidade proposta pelo paradigma informacional não comporta a dimensão da comunicação social e humana da comunicação.

Em contraponto ao paradigma informacional clássico, no paradigma relacional da comunicação, as figuras do emissor e do receptor cedem espaço para uma única representatividade, a figura do interlocutor, sujeito que participa de forma interativa e dialógica no processo comunicativo. Ou seja, o interlocutor assume o papel simultâneo de emissor e receptor de mensagens, atribuindo e criando sentido ao que é transmitido.

Considerando o ambiente organizacional e as relações sociais nele estabelecidas, a comunicação tem sentido mais holístico do que o modelo de transmissão e recepção de mensagens mecânico e hermético proposto pelo 
paradigma informacional clássico. Numa visão mais ampla e contemporânea, a comunicação seria "[...] processo social básico de produção e partilhamento do sentido através da materialização de formas simbólicas [...]” (FRANÇA, 2010, p. $41)$.

Considerando-se a discussão que circunda o paradigma relacional da comunicação no contexto organizacional, pode-se dizer que as palavras-chave que o caracteriza seriam a interação, o compartilhamento e o diálogo.

[...] estudar comunicação no contexto organizacional é analisar a relação entre sujeitos interlocutores [e podemos entender a organização como um dos interlocutores] que constroem sentido na interação que estabelecem a partir de trocas simbólicas mediadas por diferentes dispositivos, num determinado contexto. $\mathrm{O}$ fenômeno comunicacional, desta maneira, só pode ser compreendido como uma globalidade em que os elementos se afetam mutuamente e, na relação, se reconfiguram e reconfiguram a sociedade. (LIMA; BASTOS, 2008, p. 08).

Seguindo essa perspectiva dialógica, a literatura das Ciências da Comunicação também se dedica a estudar a comunicação organizacional. A importância de estudá-la está associada a aspectos próprios de suas atividades que se relacionam com a interoperabilidade das funções de comunicação e os seus mais diversos públicos.

Valentim e Zwaretch (2006, p. 46) afirmam que a CO atua como um elo para a construção das relações pessoais no ambiente corporativo, tendo em vista o processo de "[...] transferência de informação e conhecimento e a interação social organizacional [...]", por meio de fluxos formais e informais. Nesse sentido, pode-se dizer que a $\mathrm{CO}$ se tornou um elemento-chave para o entendimento dos relacionamentos ocorridos na e da organização.

Uma das principais pesquisadoras brasileiras a dedicar-se aos estudos sobre a comunicação organizacional é Margarida Kunsch. Segundo a autora,

[...] como disciplina acadêmica, [a comunicação organizacional] estuda como fenômeno comunicacional o agrupamento de pessoas que integram uma organização e que a ela se ligam em torno de uma cultura de objetivos comuns. (KUNSCH, 2008, p. 113). 
A organização, portanto, é vista como um sistema complexo e orgânico, formado por pessoas, processos, fluxos, redes, meios, instrumentos e níveis de comunicação.

Diversas ferramentas de comunicação podem ser aplicadas para identificar e atender às necessidades dos stakeholders que constituem um composto da comunicação organizacional integrada. Para garantir o fluxo de troca de informações e a interação entre os diversos departamentos que compõem uma organização, a CO se concretiza por meio de uma série de práticas e ferramentas comunicacionais. Segundo Kunsch (2008), o sincronismo do conjunto de práticas significa o momento em que os sistemas organizacionais atingem a integração de suas atividades de comunicação. Para as organizações, torna-se essencial a junção de seus processos comunicativos, em função do fortalecimento dos conceitos institucional, mercadológico e corporativo junto à sociedade.

Dentre as práticas de comunicação organizacional que se destacam, podem ser mencionadas aquelas relacionadas com a responsabilidade social corporativa (POLLACH et al., 2012), o marketing corporativo (JOHANSEN; ANDERSEN, 2012), a comunicação interna (CONSTANTIN; BAIAS, 2015; LOUHIALA-SALMINEN; KANKAANRANTA, 2012; MEN, 2015; VERCIC et al., 2012; WELCH, 2012) e as relações públicas (SELTZER et al., 2012). Este artigo privilegia e descreve a prática de comunicação interna por entender ser esta a que mais estabelece pontos de contato com os públicos internos, fomentando a criação de arenas de compartilhamento de informações e promovendo feelings motivacionais, de confiança, pertencimento, engajamento e credibilidade.

Na opinião de Kalla (2005), a comunicação interna se organiza sob quatro domínios: (1) comunicação empresarial, preocupados com a comunicação das competências dos trabalhadores; (2) a comunicação de gestão, com foco em competências de gestão e capacidades para comunicação; (3) comunicação corporativa, com foco em comunicação formal; e (4) comunicação organizacional, dirigida mais filosófica e teoricamente a questões orientadas. Tem-se, ainda, o entendimento de que a comunicação interna pode ajudar a construir compromisso pessoal e confiança na gestão, quando oferece aos funcionários meios para apontar preocupações ou sugestões. "Dar voz efetiva ao 
empregado é proporcionar a eles a oportunidade de desenvolver conhecimentos e habilidades e fazer parte da tomada de decisão.” (CONSTANTIN; BAIAS, 2015, p. 978, tradução nossa). Além disso, deve ser incentivada a comunicação direta entre gerentes e funcionários, o que potencializa o compartilhamento da informação, aumenta a confiança interna e mitiga ruídos no processo comunicativo.

Segundo Men (2015), a comunicação interna também depende do nível de engajamento dos executivos, sendo parte indispensável para a constituição e o fortalecimento da liderança organizacional. Nesse aspecto, os canais de comunicação, na direção líderes-liderados, são imprescindíveis. Como canais de comunicação, Men (2015) cita as publicações tradicionais impressas (newsletter, revistas institucionais e memorandos); telefonemas; mensagens de voz; comunicação face-a-face e ferramentas da Web 2.0 (intranet, blogs, mensagens instantâneas e sites de redes sociais internas).

Considerando os domínios da comunicação interna, sua atribuição de dar visibilidade e voz aos liderados por meio do estabelecimento de canais de comunicação traz consigo o desafio de promover uma comunicação assertiva e respaldada por valores como a motivação, a confiança, o pertencimento, o engajamento, a credibilidade e o compromisso. Welch (2012), por exemplo, enfatiza as (des)vantagens de ser adotar a prática da comunicação interna.

A comunicação interna sustenta a eficácia organizacional, uma vez que contribui para relações internas positivas, permitindo a comunicação entre os gerentes seniores e funcionários. Paradoxalmente, a comunicação interna também pode representar uma ameaça para relacionamentos organizacionais, como falta de comunicação pode ser contra-produtivo. (WELCH, 2012, p. 246, tradução nossa).

Welch (2012) defende que mensagens estratégicas emitidas pelo núcleo da comunicação corporativa interna podem seguir por até quatro caminhos, no sentido de promover ou reforçar o compromisso, a consciência, o sentimento de pertencimento ou compreensão dos funcionários e gestores de uma organização. Essas dimensões podem ser relacionadas à cultura organizacional e ao fortalecimento do engajamento e dos níveis de confiança dos funcionários, 
evidenciando a importância de uma comunicação interna estruturada e atuante. Nesses termos, essa prática de CO alinha-se ao compartilhamento da informação e à criação de conhecimento no ambiente organizacional, uma vez que oferece estratégias e ferramentas que buscam criar um ambiente oportuno para o fluxo da informação e a troca de experiências.

Ampliando a discussão para a relação entre comunicação e compartilhamento da informação, Gutiérrez-García et al. (2015) exploram o conceito de diálogo no contexto de negócio, tema interdisciplinar que engloba relações públicas, gestão de negócios e comunicação corporativa. "A primeira definição do processo dialógico é a capacidade de uma empresa de 'ouvir' seus grupos de interesse, considerando suas demandas e opiniões." (GUTIÉRREZGARCÍA et al., 2015, p. 747, tradução nossa).

Os diferentes níveis de diálogo, assim como os objetivos corporativos, permeiam todas as atividades organizacionais, incluindo o processo decisório. Entre as características do diálogo que merecem destaque está a acessibilidade, que envolve tornar a informação disponível a todos os grupos de interesse (GUTIÉRREZ-GARCÍA et al., 2015). De forma sistematizada, as dimensões e princípios do diálogo interpessoal propostos são: (1) escuta; (2) abertura para o outro; (3) busca da verdade; (4) perspectiva orientada para a mudança; e (5) resposta. Em última análise, o objetivo da comunicação corporativa é o de ser um catalisador de reforço e/ou reorientação para a mudança da cultura corporativa.

\section{Ciência da Informação: modelos informacionais e da gestão do conhecimento}

Assim como as Ciências Sociais, outra importante subárea das Ciências Sociais e Humanas é a Ciência da Informação (CI). Conforme apontam Capurro e Hjorland (2007), a agenda de pesquisa da CI se ocupa em estudar fenômenos e processos relacionados à geração, coleta, organização, interpretação, armazenamento, recuperação, disseminação, transformação e uso da informação. Sob essa concepção, o papel do sujeito na constituição do conceito de informação é vital não só como ponto de propagação, mas para processar as informações e, 
consequentemente, convertê-las em conhecimento. Logo, os aspectos semânticos e pragmáticos imbricados na informação, antes ignorados, convergiram para o surgimento de outro paradigma da informação, o cognitivo.

\begin{abstract}
Em síntese, nas diferentes subáreas da ciência da informação, durante a hegemonia da ideia de "informação e conhecimento", vigoraram sobretudo três grandes ideias: a de que o conhecimento humano é cumulativo, se dá pela entrada e processamento de novos dados; de que os sujeitos devem ser estudados em sua dimensão mentalista, isto é, como produtores e consumidores de dados, interagindo com sistemas de informação; e de que os sujeitos podem ser estudados individualmente, em seus processos de sentir falta, buscar e usar informação, para que sistemas sejam desenhados conforme suas necessidades. (ARAÚJO, 2018, p. 56).
\end{abstract}

Associado ao paradigma cognitivo da informação está o social. Nesse modelo, a Teoria Crítica se destaca, pois eleva as questões sociais ao foco das atenções. Um dos exemplos de estudos do paradigma social envolve questões como a democratização do acesso à informação e os impactos das tecnologias digitais na vida das pessoas.

Neste artigo, o paradigma da CI a ser considerado é o cognitivo, tendo em vista que a produção de conhecimento é individual e seu local de armazenamento ocorre na mente das pessoas. Conforme argumentam Capurro e Hjorland (2007, p. 174), “[...] conhecimento não pode ser gerenciado, apenas possibilitado". Concentra-se, neste ponto, uma das principais indagações da linha de pesquisa da gestão da informação e do conhecimento, que é identificar e descrever de que forma a criação e o compartilhamento do conhecimento ocorrem no ambiente organizacional.

De acordo com Sagsan (2009) é possível identificar quatro modelos relacionados à temática da gestão do conhecimento. O paradigma humanista com vínculos na Filosofia relaciona-se com a capacidade de aprendizado individual. $\mathrm{O}$

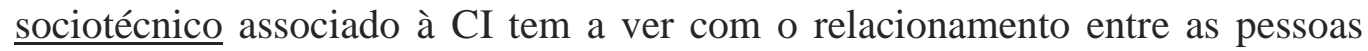
(social) e a tecnologia e recursos que permeiam o desenvolvimento de tarefas (técnico). $\mathrm{O}$ organizacional conecta-se à Administração e destaca como as pessoas compartilham a informação e criam conhecimento no ambiente organizacional. Finalmente, o tecnológico, baseado nas tecnologias de informação e 
comunicação, engloba os mecanismos de busca e recuperação de informações estruturadas.

Sagsan (2009) chama a atenção para uma análise sistêmica de fenômenos e processos relacionados à GC, combinando mais de um paradigma. Especificamente no caso deste artigo, embora o organizacional se sobressaia, o paradigma sociotécnico associa-se a ele. No estudo de caso desenvolvido, será possível observar o relacionamento dos funcionários no desenvolvimento de tarefas fomentando o compartilhamento de informação e a criação de conhecimento organizacional.

\subsection{Gestão do conhecimento: cultura organizacional e informação estratégica}

Não se pode estudar a gestão do conhecimento sem passar pelas temáticas de cultura organizacional (e informacional) e informação estratégica. Entende-se que cultura organizacional existente e efetivamente experimentada delineia a compreensão e a forma de compartilhamento de valores e crenças no ambiente corporativo. Esse compartilhamento inclui, ainda, as informações cujo a premissa estratégica culmina no desenvolvimento/aprimoramento de produtos e serviços.

Um dos principais estudiosos da cultura organizacional é Edgar Schein. Conforme esse autor,

A cultura de um grupo pode ser definida com um padrão de pressupostos básicos compartilhados que foi aprendido por um grupo para a solução de seus problemas de adaptação externa e integração interna, e que funcionou bem o suficiente para ser considerado válido e, portanto, pode ser ensinado a novos membros como a forma correta de perceber, pensar e sentir a respeito de tais problemas. (SCHEIN, 2004, p. 17).

A cultura organizacional pode ser vista como um elemento dicotômico: é capaz de ser comum a todas as organizações, ao mesmo tempo que é exclusivo, particular de cada uma delas. Conforme explicam Woida e Valentim (2006, p. 33), cultura organizacional pode ser entendida como "[...] o centro que fundamenta as demandas práticas e os objetivos organizacionais.”. Na opinião das 
autoras, a comunicação tem papel indispensável para a consolidação da cultura organizacional.

De forma semelhante, Marchiori (2006) evidencia a atuação determinante da comunicação para viabilizar a constituição da cultura organizacional, por meio da relação entre os indivíduos e a produção do conhecimento. A autora afirma que:

A formação de cultura organizacional está intimamente ligada ao processo do conhecimento e relacionamento. O diálogo, neste aspecto, é essencial e constrói os relacionamentos, gerando significados que podem ser transformados em conhecimento compartilhado, dependendo da realidade encontrada. (MARCHIORI, 2006, p. 84).

Deve ser ressaltada, ainda, a importância da comunicação no processo de construção de significados, tendo em vista o aspecto da interação social da organização. A construção de significados, por sua vez, está entre os processos relacionados à informação vista como estratégica, conforme aponta Choo (1998). Segundo o autor, os processos de interpretação das notícias e mensagens (fase de criação de significado), o de conversão do conhecimento (etapa de construção de conhecimento) e o de processamento e a análise da informação (tomada de decisão) são fundamentais para a ocorrência do compartilhamento de informação e da criação de conhecimento.

Nonaka e Takeuchi (1995) discutem a teoria de criação de conhecimento e apresentam as características que definem uma organização criadora do conhecimento. Segundo eles, a criação de conhecimento organizacional depende da participação de pessoas que, de forma criativa, constroem contextos para a troca de informações. Ainda segundo os autores, há uma distinção entre conhecimento tácito e conhecimento explícito. O tácito é pessoal, específico ao contexto e difícil de ser formalizado e comunicado; já o explícito, refere-se ao conhecimento que pode ser transmitido através de uma linguagem formal e sistemática (NONAKA; TAKEUCHI, 1995).

O contraponto entre esses dois tipos de conhecimento - tácito e explícito - inspirou os autores a elaborarem e descreverem os modos de conversão do conhecimento, quais sejam: a socialização, a externalização, a combinação e a 
internalização. Segundo Nonaka e Takeuchi (1995), as modalidades permitem: (1) socializar: o conhecimento tácito pode ser apreendido de um indivíduo para o outro por meio do compartilhamento de experiências, tornando-se, assim, explícito; (2) externalizar: movimento de tornar explícito um conhecimento tácito, a partir da formalização de modelos, conceitos ou hipóteses, por exemplo; (3) combinar: troca de conhecimentos que já estão formalizados e registrados em documentos; e (4) internalizar: processo de conversão do conhecimento explícito ao tácito relacionado à expressão "aprender fazendo". Os modos de conversão do conhecimento culminam no que os autores definem como espiral do conhecimento. A espiral remete à imagem de um movimento dinâmico e progressivo, no qual ocorre uma interação contínua entre os conhecimentos tácito e explícito.

O modelo de processo de GC proposto por García-Fernández (2015) indica três etapas para a criação de conhecimento. $\mathrm{Na}$ fase denominada "criação de conhecimento", o autor faz referência à interpretação coletiva das informações disseminadas. Na etapa de "armazenamento e transferência do conhecimento", uma das maneiras indicadas para se transferir o conhecimento organizacional é por meio da externalização, num movimento que ocorre no sentido da organização para o coletivo e consolida-se no trabalho em equipe, projetado na fase de “implementação e uso do conhecimento". Além disso, no que diz respeito ao armazenamento do conhecimento, a memória coletiva torna-se um elemento fundamental nesse processo.

$\mathrm{O}$ aspecto da coletividade presente no processo de GC emerge também nas pesquisas de Dixon e Stroh (2017) para os quais a GC está em constante mudança desde 1995, quando ocorreu a popularização do termo associado às expressões "trabalhadores do conhecimento" e "economia do conhecimento", ambos propostos por Peter Drucker. Os autores definem as "Três Eras do Gerenciamento do Conhecimento", três estágios com níveis distintos de GC (DIXON; STROH, 2017).

A Era 1 refere-se à gestão da informação, à preocupação de as organizações documentarem e arquivarem seus conhecimentos para que possam ser acessados sempre que necessário. A Era 2, da Gestão da Experiência, 
proporcionou uma calibragem de interesses, dos registros em documentos para o aprendizado através do intercâmbio de experiências internas. A identificação de fatores limitantes conduziu a uma nova perspectiva, o surgimento da Era 3, a da Gestão de Ideias. Conforme demonstrado no diagrama de Dixon e Stroh (2017), o foco volta-se para a gestão do conhecimento coletivo com vistas à resolução de problemas organizacionais.

Os modelos de García-Fernández (2015) e Dixon e Stroh (2017) enfatizam a proposição de geração endógena do conhecimento, bem como expõem o aspecto da coletividade. De forma complementar, vale enfatizar, ainda, um elemento fundamental para o entendimento da gestão do conhecimento: o " $b a$ ", assimilado no Brasil como "contexto capacitante". Segundo Nonaka e Konno (1998), o conceito de " $b a$ ", originalmente proposto pelo filósofo japonês Kitaro Nishida, pode assumir conotações relacionadas ao tipo de contexto, podendo ser ele físico, virtual, mental ou um mix entre eles.

Na esteira dos estudos de Nonaka e Takeuchi (1995) e Nonaka e Konno (1998), Alvarenga Neto (2018, p. 133) destaca que a formação de contexto capacitante se diferencia do estabelecimento da interação humana rotineira e defende que "não há inovação sem um 'ba'.”. Ainda segundo o autor, existiriam quatro grupos de condições capacitadoras, sendo eles: o sociocomportamental (normas e valores institucionais), o cognitivo-epistêmico (ideias e crenças compartilhadas), o informacional/comunicacional (ferramentas e aplicativos de tecnologias e sistemas de informação) e o estratégico-estrutural-sistêmico de gestão (práticas e processos). Levantamento bibliográfico feito pelo autor acerca dessa temática apontou que:

[...] "contexto capacitante" ou "Ba" de uma organização do conhecimento é composto de: (a) quatro grandes grupos de condições capacitadoras [...]; (2) que podem ser livremente combinados em diferentes processos estratégicos de conhecimento - criação, compartilhamento/transferência e uso; (3) e que ocorrem em diferentes níveis de interação - indivíduos, equipes, organizações e interorganizações/redes. (ALVARENGA NETO, 2018, p. 140, grifos do autor).

Como possíveis resultados das condições capacitadoras, Alvarenga Neto (2018) cita a criação de oportunidades de diálogo e a construção de confiança 
mútua (sociocomportamental), as mudanças na estrutura das equipes e a introdução de modelos mentais (cognitivo epistêmico), o uso de ferramentas de informação e comunicação assertivas (informacional/comunicacional), a identificação de "ativistas da inovação" e a criação de calendário de reuniões (estratégico-estrutural-sistêmico de gestão). Neste artigo, tem-se a intenção de apresentar um exemplo da formação de contexto capacitante.

\section{Metodologia}

Este estudo descritivo alinha-se à pesquisa qualitativa, que almeja um aprofundamento de compreensão sobre determinada organização. Essencialmente, buscou-se identificar e correlacionar abordagens gerenciais entre duas áreas interdisciplinares. No que se refere aos procedimentos, o artigo utiliza a estratégia do Método do Estudo de Caso, tipificado como históricoorganizacional (YIN, 2015).

A amostra foi definida de forma intencional e selecionou uma organização dotada de áreas, programas, projetos ou iniciativas de compartilhamento de informação e criação de conhecimento, além de um setor de comunicação organizacional próprio, estruturada e atuante. $\mathrm{O}$ estudo de caso foi desenvolvido na Localiza, empresa cujo principal negócio é a locação de veículos e que contava, na época em que a pesquisa foi realizada, com quase 600 agências (filiais e franqueadas), em mais de 400 cidades brasileiras e em outros seis países da América Latina.

A principal estratégia de análise utilizada foi a descrição do caso. Por se tratar de um estudo qualitativo, apresenta-se uma análise interpretativa. As principais fontes de evidências foram a documentação, a observação direta e a entrevista. Nas três situações, os acessos e os agendamentos foram solicitados formalmente e autorizados pela organização estudada. O principal instrumento de coleta de dados foi o roteiro aberto de entrevista, aplicado a nove profissionais. A observação direta foi realizada de maneira informal, mediante a participação da pesquisadora em atividades organizacionais coletivas programadas. 
Importante registrar que a pesquisa foi aprovada e realizada em concordância com as recomendações do Comitê de Ética Em Pesquisa da Universidade Federal de Minas Gerais (COEP - UFMG).

\subsection{Apresentação do contexto corporativo}

A empresa Localiza está estruturada em quatro linhas de negócio: aluguel de veículos, locação de veículos, gestão de frotas e divisão de negócios, voltada para clientes corporativos que desejam terceirizar suas frotas. A visão, missão e princípios da empresa devem ser destacados porque as iniciativas de gestão e compartilhamento do conhecimento investigadas têm como ponto de origem as diretrizes previstas no plano estratégico da empresa, desdobrado deste quadro. A Localiza tem como visão ser uma empresa admirada. A missão, por sua vez, é contribuir para o sucesso dos negócios e lazer dos clientes, alugando carros com eficiência e simpatia. Já os princípios são: a valorização do cliente, o reconhecimento ao desempenho dos colaboradores, o comportamento ético, o zelo pela imagem da empresa, a busca da excelência e o objetivo de agregar valor à empresa.

Dos nove profissionais consultados, três estão enquadrados no nível gerencial, um no de especialista, quatro no de analista e um no de assistente. Os profissionais estão lotados na sede da empresa, em Belo Horizonte. Nas entrevistas realizadas no primeiro semestre de 2018, os participantes falaram sobre as três iniciativas de GC identificadas.

A primeira delas é o Programa Qualificar. Criado em 2012 pela área de Desenvolvimento de Pessoas, vinculada à Diretoria de Recursos Humanos, oferece treinamentos para colaboradores de todo o Brasil, por meio de um time de instrutores formado pelos próprios funcionários. Além dos treinamentos presenciais, utiliza ferramenta de e-learning para dar capilaridade ao programa e alcançar as filiais pelo país. É considerado uma ferramenta de gestão de pessoas com alto potencial de estímulo de compartilhamento de informação. A cada semestre, são ofertadas vagas para uma grade específica de cursos pautados nos 
valores organizacionais, no direcionamento estratégico, no modelo de competências e na análise dos pontos mapeados na Avaliação de Desempenho.

O Prosa com o CEO, por sua vez, é uma iniciativa da Gerência de Comunicação Corporativa que consiste na realização de encontros informais entre o executivo da empresa e colaboradores inscritos. O programa foi criado em 2016 e é realizado mensalmente na matriz e nas filiais. A prioridade do Programa é formar um público multidisciplinar, para socializar a diversidade de realidades e tornar o encontro mais rico. Cada sessão conta com 15 participantes, inscritos voluntariamente pela internet. O programa é tido como uma ferramenta de gestão, na medida em que personifica o executivo, aproximando-o dos colaboradores e oferecendo um canal de comunicação. O caráter institucional desses encontros como canais de comunicação é bastante visível, apesar disso, pode ser considerado uma demonstração de interesse e de disposição da própria empresa em ter contato com colaboradores.

O Programa Sala de Projetos Sistêmicos é iniciativa da Diretoria de Gestão de Projetos e de Sistemas para a execução de um projeto ágil. Trata-se da adoção da metodologia inception, resultado de um mix das metodologias focadas no conhecimento e na experiência dos participantes. Busca-se desenvolver e entregar uma solução, geralmente de TI, concretizada em um Produto Mínimo Viável (MVP). As tarefas da metodologia inception são realizadas por uma equipe multidisciplinar, contando com responsáveis pelo negócio/produto/serviço e por colaboradores de áreas distintas e diretamente relacionadas ao projeto. A equipe é responsável por todas as etapas, que vão do diagnóstico do problema à validação da solução, em um curto espaço de tempo. Todas as etapas são executadas em uma semana intensa de atividades colaborativas.

\section{Discussão dos dados}

$\mathrm{O}$ estudo permitiu visualizar um exemplo de interface entre práticas de $\mathrm{CO}$ e iniciativas de GC. Foram identificados três programas da empresa como sendo iniciativas de GC: o Qualificar, o Prosa com o CEO e o Sala de Projetos 
Sistêmicos. Na análise, procurou-se destacar a ocorrência do compartilhamento de informação e a criação de conhecimento e identificar os modos de conversão do conhecimento (NONAKA; TAKEUCHI, 2008), descrever situações de transformação de conhecimento individual para o conhecimento em grupo (GARCÍA-FERNÁNDEZ, 2015) e pontuar a participação da comunicação organizacional para o êxito das iniciativas (KUNSCH, 2009; WELCH, 2012). As inferências da interface entre as áreas estão sistematizadas na Figura 1.

Figura 1 - Interface entre áreas

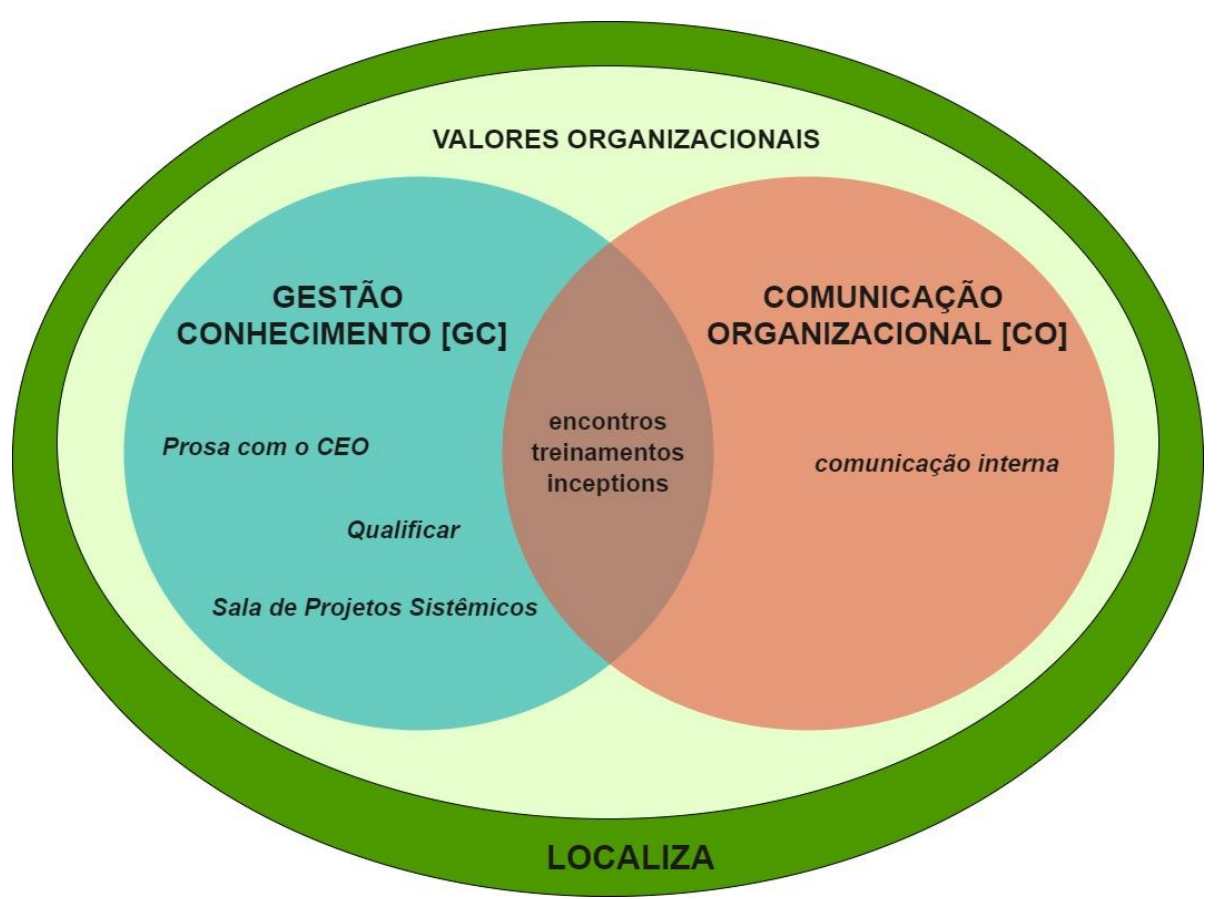

Fonte: Elaborado pelos autores (2020).

O contexto organizacional é onde o estudo de caso foi realizado, a Localiza. O espaço considera o ramo de atuação, o quadro de funcionários e o fato de sua composição advir de uma plataforma de quatro frentes: aluguel de veículos, gestão de frotas, franchising e seminovos. $\mathrm{Na}$ área interna, está a cultura organizacional com bases sólidas nos valores organizacionais da empresa: valorização do cliente; reconhecimento ao desempenho dos colaboradores; comportamento ético; zelo pela imagem da empresa; busca da excelência; e agregação de valor à empresa. $\mathrm{O}$ diagrama não considera $\mathrm{o}$ contexto organizacional externo, exatamente por enfocar processos internos. 
Ao centro da figura, estão os contextos capacitantes, momentos-chave de cada um dos programas listados. Do Qualificar, tem-se os treinamentos; do Sala de Projetos Sistêmicos, os inceptions; e do Prosa com o CEO, os encontros de bate-papo. Esses espaços primam pela interação presencial entre os interlocutores (organização-empregados), reiterando o aspecto relacional do processo comunicativo organizacional. Os contextos capacitantes são dimensões dialógicas e organizacionais que assumem o papel de interface entre as duas grandes áreas da pesquisa. Ou seja, as iniciativas de GC identificadas dependem de práticas da comunicação organizacional para existirem.

Tais iniciativas de GC apresentam características comuns: a reunião presencial de profissionais de áreas distintas, permitindo a formação de equipes multidisciplinares, em espaços comuns de diálogo, evidenciando a interface organização-empregado. Essas características estão associadas ao entendimento de gestão do conhecimento, no que diz respeito à gestão organizacional de contextos capacitantes. Nos três programas há referências a um " $b a$ " físico associado ao mental: profissionais reunidos no mesmo espaço, trocando experiências (Qualificar e Prosa com o CEO) e ideias (Sala de Projetos Sistêmicos). As iniciativas ilustram contextos capacitantes que consideram normas e valores institucionais, ideias e crenças compartilhadas, ferramentas e aplicativos de tecnologias e sistemas de informação e práticas e processos (ALVARENGA NETO, 2018).

Nessa perspectiva, a comunicação interna assume duplo papel: de promotora, ao criar um programa de relacionamento entre a diretoria-executiva e colaboradores, e de difusora, ao trabalhar de forma conjunta com as áreas de RH e de gestão de processos, divulgando as atividades para garantir a adesão os participantes. Além disso, mesmo quando as práticas de comunicação não são executadas por um profissional de comunicação, ferramentas da CO são postas em prática. Como exemplo, citam-se a elaboração do release ao fim de um inception, e o registro audiovisual de atividades (memória organizacional).

É na zona de interface entre CO e GC que se observa o compartilhamento da informação e a criação de conhecimento organizacional da Localiza, processo chamado no mapa integrado de transferência do conhecimento. A riqueza desses 
encontros está exatamente em agrupar pessoas de áreas distintas, permitindo que informações corporativas e rotinas de trabalho sejam compartilhadas e, mais tarde, incorporadas às condutas de cada um dos colaboradores, num processo de socialização e internalização. Por outro lado, institucionalmente, as equipes multidisciplinares também colaboram para que valores organizacionais ganhem mais circularidade e sejam ainda mais fortalecidos internamente.

Tem-se, na força dos valores organizacionais, outra constatação. O alinhamento de discurso entre os entrevistados é bastante visível, mesmo quando foram feitas críticas à empresa e ao escopo de comunicação organizacional. Atribui-se isso à força da cultura professada na empresa. Duas características podem ser conferidas à cultura organizacional da Localiza: a capilaridade, permitindo que os valores corporativos cheguem a toda plataforma de negócios, da matriz às filiais; e o nivelamento, fazendo com que as diretrizes do planejamento estratégico sejam repassadas da diretoria-executiva aos colaboradores. Segundo a Entrevistada 9, cultura organizacional e planejamento estratégico são os dois grandes pilares da empresa.

Tudo que a gente faz ou está ancorado no direcionamento estratégico, que é um reflexo da cultura que a gente quer construir, ou está ancorado nos valores da Localiza. Eu acho que o que nos leva a isso é o discurso, a comunicação, a consistência. Nosso quadro de valor não está pregado na parede só, simplesmente. Nossa grade de valores é percebida de fato na organização. A gente tem sim consistência no discurso, no speech, no alinhamento, mas também tem uma consistência com a prática. (E9).

A consistência da cultura organizacional não quer dizer engessamento.

Como observa a Entrevistada 2, a empresa preocupa-se em se atualizar e fazer redirecionamentos.

\footnotetext{
A Localiza existia um pouco em torno de si mesma. Hoje eu vejo que mais um olhar para fora. Eu estou aqui há muitos anos e pude perceber isso: a gente olha muito mais hoje para o concorrente, a gente se preocupa com ele, a gente quer estar à frente. Acho que toda essa mudança maior que está acontecendo realmente possibilitou que a gente trouxesse a metodologia do inception. Essa que eu acho que foi a grande mudança, conseguir estar junto com esse cliente, trazer esse insumo que é riquíssimo e construir a solução em cima da voz do cliente. Hoje tem uma cultura muito mais aberta, muito mais propensa a novas práticas, a abordagens e formas até de nos relacionarmos internamente. (E2).
} 
A fala explicita o princípio organizacional de valorização do cliente. Ao longo das entrevistas, os demais valores corporativos se fizeram presentes, como o reconhecimento ao desempenho dos colaboradores. Para exemplificar, tem-se a narrativa de experiência da Entrevistada 8 com o Qualificar: "Fazemos cerimônia de entrega certificado, mas não sei se todos os setores da companhia têm essa adesão. Você percebe que a decisão do seu setor é muito boa.” A respondente acredita que os treinamentos oferecidos contribuem para os desenvolvimentos pessoal e profissional dos colaboradores, afirmando com orgulho: "Eu tenho quase toda a grade completa. Quase toda!” (E8).

O Entrevistado 6, por sua vez, destaca a motivação:

Desde que eu entrei, a empresa se preocupa muito em capacitar os instrutores. Então ela oferece muitos cursos de capacitação, cursos estes que se eu resolvesse fazer, de certa forma, eu iria investir muito, então acho que é o principal motivador. Além deste, claro, aquilo é importante para a sua carreira. É muito importante então você estar se capacitando e isso é muito bom. Essa troca é muita boa. Não necessariamente eu preciso ganhar isso em valor financeiro, mas em conhecimento acho que vale (E6).

Reconhecimento e orgulho foram aspectos bastante enfatizados pelos respondentes, demonstrando um forte indício de internalização de valores corporativos. Outros temas recorrentes foram protagonismo e confiança. Alguns temas, não enfatizados nas entrevistas, foram perceptíveis. O primeiro deles é o controle da empresa exercido nos colaboradores. Sobre esse tema, a Entrevistada 9 fez a seguinte ponderação:

As competências são oriundas dos valores corporativos, o que a gente quer de conduta do colaborador, de comportamento dele para atingir o resultado. Então ele recebe metas no início do ano, que é o que ele tem que entregar. Ele sabe quais são as competências necessárias para o cargo dele, que dizem como ele deve entregar. Então, isso pereniza a cultura, porque o "nosso" "como" tem uma maneira peculiar, que é diferente de outras empresas (E9).

No caso do Qualificar, mesmo sendo oferecida ao colaborador a chance de selecionar o seu curso, cabe ao seu gestor imediato validar ou não a inscrição. E, segundo relatos, o cancelamento de inscrição já ocorreu: 
O programa não é perfeito, principalmente em uma empresa tão grande como esta. Só aqui, na matriz, temos mais de 150 líderes, como é que você controla o que cada um está fazendo? E o líder, como dissemos, não é perfeito, mas ele vem com essa orientação de explicar porquê se deve e porquê não se deve fazer o treinamento. E em muitos casos, pessoas entendem. A gente não tem tido reclamações dos colaboradores nesse sentido (E1).

Diante desse posicionamento, fica suspensa uma indagação: em uma situação de desautorização, qual colaborador reclamaria? Das entrevistas realizadas, não há elementos sólidos para se discorrer sobre este questionamento.

Outro aspecto extraído das narrativas dos respondentes está contido exatamente na fala relacionada à liderança. Por exemplo, o depoimento a seguir destaca esta questão:

Tinha muita a questão da rádio peão, de pessoas insatisfeitas. Um trabalho que tive que fazer com os líderes foi fazer as informações chegarem às pessoas, agir com transparência. Se não tem uma reunião da área, vai demorar, então faz uma reunião relâmpago, mas não deixe de comunicar. Essa é uma pauta que eu tive que trabalhar muito com eles. A gente ainda precisa atuar mais nisso, para que as informações cheguem a tempo e a hora para eles. E o líder também, ele é um agente muito poderoso de comunicação. É ele que tem esse papel de levar para as equipes também. Todos os líderes tiveram que passar por esse treinamento [Líder Comunicador], que foi organizado dentro do programa Qualificar (E5).

Ainda de acordo com a respondente, existe uma grade de cursos específica, fora do Qualificar, voltada para a promoção do desenvolvimento da liderança de profissionais nos cargos de gerência. Isso porque o programa atende especialmente analistas e especialistas. "São assistentes, pessoal do administrativo, esse público mais simples, digamos assim, e o call center, quando podem participar.", explica a Entrevistada 5. Assim, no treinamento "Liderança para não líderes" do Qualificar, trabalham-se habilidades em pessoas que são referências técnicas nas áreas e que precisam exercer papel de liderança.

As atividades organizadas e oferecidas de forma estruturada e hierárquica demonstram a visão da empresa em fortalecer a sua presença internamente, ampliando sua rede de escuta, buscando o nivelamento de informações e a construção de sentido em seu contexto organizacional. O diálogo formal e institucional entre tais interlocutores é um dos mecanismos utilizados para que esses objetivos sejam alcançados. Assim, tem-se o entendimento de que o controle 
é exercido pelos líderes, que passam por capacitação para o desenvolvimento de habilidades específicas e estratégicas relacionadas à liderança. Pode-se dizer que a empresa se preocupa com os papéis organizacionais desempenhados por seus colaboradores, de forma geral. Ao longo das narrativas, são destacados os papéis interpessoais, de informação e de decisão (MINTZBERG, 2003).

Os aspectos da coletividade e do diálogo, presentes nas iniciativas de GC analisadas, também podem ser associados às eras do gerenciamento do conhecimento de Dixon e Stroh (2017), em especial, às referências ao gerenciamento de experiências e de ideias. Pode-se dizer que os três programas da Localiza se posicionam como ferramentas que buscam gerenciar vivências, por meio de relatos dos participantes que narram situações individuais e profissionais. Especialmente no caso da Sala de Projetos Sistêmicos, observa-se ainda um nível mais avançado de gestão do conhecimento, por meio do gerenciamento de ideias ocorrido durante processos de resolução de problemas organizacionais.

\section{Considerações finais}

$\mathrm{O}$ artigo evidenciou que práticas da comunicação organizacional promovem ou subsidiam o compartilhamento de informação e a criação de conhecimento organizacional, sobretudo diante da importância da comunicação interna no que diz respeito à promoção do compromisso do colaborador com a organização, da consciência dos membros internos sobre as mudanças de ambiente, da compreensão da evolução dos objetivos organizacionais e a promoção da sensação de pertencimento. Conforme evidenciado, um clima organizacional favorável e bons índices de engajamento e confiança dos colaboradores são essenciais para que a gestão do conhecimento ocorra.

$\mathrm{O}$ estudo demonstrou o exemplo de interface entre as áreas de $\mathrm{CO}$ e GC, então representada pela aproximação das áreas da comunicação corporativa, responsável pelas atividades da comunicação interna, e das iniciativas de GC. Essa zona de conexão são os contextos capacitantes físico-mentais, espaços organizacionais dialógicos nos quais a gestão do conhecimento se concretiza. 
O estudo destaca a importância da atuação consistente da comunicação organizacional no fortalecimento de diretrizes internas e no suporte e/ou promoção conjunta com outras áreas para se ampliar a formação de contextos capacitantes e, assim, fomentar o compartilhamento da informação e a criação de conhecimento organizacional. Além disso, evidencia os paradigmas relacional da comunicação (figura dos interlocutores) e organizacional da gestão do conhecimento (processos de compartilhamento de informação e criação de conhecimento corporativo).

Nos relatos, expressões como autonomia, criatividade, experimentação, encontro e diálogo foram bastante recorrentes. No entanto, tais expressões e seus respectivos posicionamentos, de certa forma, sombreiam temáticas contrapostas como hierarquização, controle, conflitos comunicacionais, que foram sendo citadas nas entrevistas e cabe problematizá-las. Nota-se certa romantização nas falas que ressaltam a importância do direcionamento da empresa ao diálogo interno, seja por meio da abertura de canais de comunicação, seja por meio do estabelecimento de contextos capacitantes.

$\mathrm{O}$ aspecto da força da cultura organizacional, do sistema de crenças e valores da empresa é evidente. Como consequência, ter "sangue verde", em alusão à cor predominante da logomarca da Localiza, direciona e, por vezes, condiciona os comportamentos dos empregados. Há direcionamentos para a competitividade, por exemplo, ser um instrutor do Qualificar torna-o mais conhecido, ter uma ideia assertiva no Sala de Projetos Sistêmicos torna-o mais produtivo, participar de um Conversa com o CEO torna-o mais engajado. No pano de fundo, está a cultura organizacional, subsidiada em controle de vontades e poder de decisão. O sentimento de pertencimento apontado nas falas, por sua vez, pode ser visto como uma espécie de anestésico, minimizando os efeitos do controle e da hierarquização.

Apesar de os resultados de um estudo de caso único não poderem ser generalizados, o exemplo de interface demonstrado nesta pesquisa reconhece e legitima ferramentas de comunicação organizacional como elementos essenciais para o sucesso das iniciativas de gestão do conhecimento no contexto organizacional. Da mesma forma, os procedimentos metodológicos definidos e 
aplicados na presente investigação podem servir de referencial para estudos em outras empresas com o mesmo perfil ou com perfis distintos.

\section{Financiamento}

Este artigo é resultado de pesquisa de doutorado em Ciência da Informação, realizada por meio de financiamento do Conselho Nacional de Desenvolvimento Científico e Tecnológico (CNPq).

\section{Referências}

ALVARENGA NETO, R. C. D. de. Fazendo a inovação acontecer. São Paulo: Planeta, 2018.

ARAÚJO, C. A. A. Um mapa conceitual da Ciência da Informação: história, subáreas e paradigmas. Convergências em Ciência da Informação, São Cristóvão, v. 1, n. 1, p. 45-70, jan./abr. 2018.

BARRETO, A. A condição da informação. In: STAREC, C.; GOMES, E. B. P.; CHAVES, J. B. L. (org.). Gestão estratégica da informação e inteligência competitiva. São Paulo: Saraiva, 2005. p. 3-16.

CAPURRO, R.; HJORLAND, B. O conceito de informação. Perspectivas em Ciência da Informação, Belo Horizonte, v. 12, n. 1, p. 148-207, jan./abr. 2007.

CHOO, C. W. The knowing organization: How organizations use information to construct meaning, create knowledge, and make decisions. New York: Oxford University Press, 1998.

CONSTANTIN, E. C.; BAIAS, C. C. Employee voice-key factor in internal communication. Procedia - Social and Behavioral Sciences, [s. l.], n. 191, p. 975-978, 2015.

DAVENPORT, T. H.; PRUSAK, L. Working knowledge: How organizations manage what they know. Brighton: Harvard Business Press, 1998.

DIXON, N.; STROH, J. The three eras of knowledge management. Common Knowledge Associates, [s. l.], 2017. Disponível em:

http://www.commonknowledge.org/the-3-eras-of-km.html. Acesso em: 09 fev. 2021. 
DRIGO, E. et al. Analysis of operational communication throught structural equation modeling. IEEE Access, [s. l.], v. 8, p. 121705-121723, 2020.

FRANÇA, V. V. O objeto da comunicação/a comunicação como objeto. In: HOHLFELDT, A.; MARTINO, L. C.; FRANÇA, V. V. (org.). Teorias da comunicação: conceitos, escolas e tendências. 10. ed. Petrópolis: Vozes, 2010. p. 39-60.

GARCÍA-FERNÁNDEZ, M. How to measure: knowledge management: dimensions and model. Vine, [s. l.], v. 45, n. 1, p. 107-125, 2015.

GUTIÉRREZ-GARCÍA, E. et al. Reinventing the wheel?: a comparative overview of the concept of dialogue. Public Relations Review, [s. l.], v. 41, n. 5, p. 744-753, dez. 2015.

JOHANSEN, T. S.; ANDERSEN, S. E. Co-creating ONE: rethinking integration within communication. Corporate Communications: An International Journal, [s. l.], v. 17, n. 3, p. 272-288, 2012.

KALLA, H. K. Integrated internal communications: a multidisciplinary perspective. Corporate Communications: An International Journal, [s. l.], v. 10, p. 302-314, 2005.

KUNSCH, M. M. K. Planejamento estratégico da comunicação. In: KUNSCH, M. M. K. (org.). Gestão estratégica, comunicação organizacional e relações públicas. Caetano do Sul: Difusora Editora, 2008. p. 107-124.

LIMA, F.; BASTOS, F. Comunicação no contexto organizacional: afinal, o que é mesmo que estudamos? In: CONGRESSO BRASILEIRO DE CIÊNCIAS DA COMUNICAÇÃO, 31., 2008, Natal. Anais [...]. São Paulo: INTERCOM, 2008. p. $1-15$.

LOUHIALA-SALMINEN, L.; KANKAANRANTA, A. Language as an issue in international internal communication: English or local language? If English, what English?. Public Relations Review, [s. l.], n. 38, p. 262-269, 2012.

MARCHIORI, M. Cultura Organizacional: um olhar estratégico sobre a organização. São Caetano, São Paulo: Difusão Editora, 2006.

MEN, L. R. The internal communication role of the chief executive officer: communication channels, style, and effectiveness. Public Relations Review, $[s$. l.], n. 41, p. 461-471, 2015.

MINTZBERG, H. Criando organizações eficazes. 2. ed. São Paulo: Atlas, 2003. 
NONAKA, I.; KONNO, N. The concept of "ba": Building a foundation for knowledge creation. California Management Review, [s. l.], n. 40, p. 40-54, 1998.

NONAKA, I.; TAKEUCHI, H. The knowledge creating company: How japanese companies create the dynamics of innovation. New York: Oxford University Press, 1995.

PIZZAIA. A. et al. O papel da comunicação na gestão do conhecimento: aspectos relevantes e estímulo a novas pesquisas. Perspectivas em Gestão \& Conhecimento, João Pessoa, v. 8, n. 2, p. 62-81, maio/ago. 2018.

POLLACH, I. et al. The integration of CSR into corporate communication in large European companies. Journal of Communication Management, [s. l.], v. 16, n. 2, p. 204-216, 2012.

SAGSAN. M. Knowledge management discipline: test for an undergraduate program in Turkey. Electronic Journal of Knowledge Management, Sonning Common, [s. l.], v. 7, n. 5, p. 627-636, 2009.

SCHEIN, E. H. Cultura organizacional e liderança. São Paulo: Atlas, 2004.

SELTZER, T. et al. PR in the ER: managing internal organization-public relationships in a hospital emergency department. Public Relations Review, [s. l.], n. 38, p. 128-136, 2012.

SHANNON, C.; WEAVER, W. The mathematical theory of communication. Urbana: University of Illinois Press, 1972.

SIMON, H. A. Comportamento administrativo. 2. ed. Rio de Janeiro: Fundação Getúlio Vargas, 1971.

VALENTIM, M. L. P.; ZWARETCH, N. S. Comunicação organizacional/Comunicação informacional no processo de inteligência competitiva organizacional. In: VALENTIM, M. L. P. (org.). Informação, conhecimento e inteligência organizacional. 2. ed. Marília: FUNDEPE, 2006. p. 45-59.

VERCIC, A. T. et al. Internal communication: definition, parameters, and the future. Public Relations Review, [s. l.], n. 38, p. 223-230, 2012.

WELCH, M. Appropriateness and acceptability: employee perspectives of internal communication. Public Relations Review, [s. l.], n. 38, p. 246-254, 2012.

WOIDA, L. M.; VALENTIM, M. L. P. Cultura organizacional/Cultura informacional: a base do processo de inteligência competitiva organizacional. 
In: VALENTIM, M. L. P. (org.). Informação, conhecimento e inteligência organizacional. 2. ed. Marília: FUNDEPE, 2006. p. 25-44.

YIN, R. K. Estudo de caso: planejamento e métodos. 5. ed. Porto Alegre:

Bookman, 2015.

\title{
Organizational Communication and Knowledge Management: interface between areas
}

\begin{abstract}
The paper reports a research, of an interdisciplinary nature, that describes management practices, approaches, and interfaces between organizational communication and knowledge management in a company of the service sector and car rental products. The data obtained endorses the relational paradigms of communication and organizational knowledge as the most appropriate for the promotion of interpersonal dialogue in the work environment. The study highlights the importance of the formation of a "ba" conducive to the sharing of information and the creation of knowledge within the studied organization. The results show that the "ba" stimulates the promotion of commitment of internal audiences to the organization, awareness of changes in the corporate environment, an understanding of the evolution of organizational objectives and a feeling of belonging to the organization. The results also demonstrate the relevance of internal communication for the sharing of information and the creation of organizational knowledge.
\end{abstract}

Keywords: Internal communication. Information sharing. Knowledge creation. Ba. Interdisciplinarity.

Recebido: 04/06/2020

Aceito: $14 / 08 / 2020$

\section{Declaração de autoria}

Concepção e elaboração do estudo: Ariane Barbosa Lemos

Coleta de dados: Ariane Barbosa Lemos

Análise e discussão de dados: Ariane Barbosa Lemos

Redação e revisão do manuscrito: Ariane Barbosa Lemos e Ricardo Rodrigues Barbosa

\section{Como citar}

LEMOS, Ariane Barbosa; BARBOSA, Ricardo Rodrigues. Comunicação Organizacional e Gestão do Conhecimento: interface entre áreas. Em Questão, Porto Alegre, v. 27, n. 2, p. 267-293, abr./jun. 2021.

Doi: http://dx.doi.org/10.19132/1808-5245272.267-293 